\title{
Article
}

\section{A Semester-Long Project for Teaching Basic Techniques in Molecular Biology Such as Restriction Fragment Length Polymorphism Analysis to Undergraduate and Graduate Students}

\section{Susan M. DiBartolomeis}

Department of Biology, Millersville University, Millersville, PA 17551-0302

Submitted July 30, 2010; Revised October 8, 2010; Accepted October 14, 2010

Monitoring Editor: Debra Tomanek

\begin{abstract}
Several reports on science education suggest that students at all levels learn better if they are immersed in a project that is long term, yielding results that require analysis and interpretation. I describe a 12-wk laboratory project suitable for upper-level undergraduates and first-year graduate students, in which the students molecularly locate and map a gene from Drosophila melanogaster called dusky and one of dusky's mutant alleles. The mapping strategy uses restriction fragment length polymorphism analysis; hence, students perform most of the basic techniques of molecular biology (DNA isolation, restriction enzyme digestion and mapping, plasmid vector subcloning, agarose and polyacrylamide gel electrophoresis, DNA labeling, and Southern hybridization) toward the single goal of characterizing dusky and the mutant allele dusky ${ }^{73}$. Students work as individuals, pairs, or in groups of up to four students. Some exercises require multitasking and collaboration between groups. Finally, results from everyone in the class are required for the final analysis. Results of pre- and postquizzes and surveys indicate that student knowledge of appropriate topics and skills increased significantly, students felt more confident in the laboratory, and students found the laboratory project interesting and challenging. Former students report that the lab was useful in their careers.
\end{abstract}

\section{INTRODUCTION}

The discipline of molecular biology is heavily technique dependent. Teaching students the "how-tos" of these techniques can be done in a laboratory setting with a technique taught per laboratory period, but in doing such singular lab exercises, students would miss when and why these techniques are performed. Rather, using a project approach in which students have a major goal that requires a whole set of methods and techniques following each other in logical progression

DOI: $10.1187 /$ cbe.10-07-0098

Address correspondence to: Susan M. DiBartolomeis (sdibarto@ millersville.edu).

(C) 2011 S. M. DiBartolomeis. CBE_Life Sciences Education (c) 2011 The American Society for Cell Biology. This article is distributed by The American Society for Cell Biology under license from the author(s). It is available to the public under an AttributionNoncommercial-Share Alike 3.0 Unported Creative Commons License (http:/ / creativecommons.org/licenses/by-nc-sa/3.0).

"ASCB ${ }^{\circledR}$ " and "The American Society for Cell Biology ${ }^{\circledR}$ " are registered trademarks of The American Society for Cell Biology. would expose students to a more realistic research situation. Inquiry-based and project approach formats of laboratories for high school students and undergraduates have been recommended by several groups of educators (Howard Hughes Medical Institute, 1996; Allen and Tanner, 2003; National Research Council [NRC], 2003; Bhattacharjee, 2005; Shane, 2009). Project-based labs are thought to engage students more readily than "cookbook" labs; they often yield data that require more analysis and interpretation than data generated from isolated laboratory experiments. Additionally, lab projects have the potential to foster opportunities in scientific writing and collaboration and incorporate interdisciplinary approaches (NRC, 2003). In keeping with these recommendations, many project-based laboratories and courses designed to hone investigative skills have been established (DiBartolomeis and Moné, 2003; Mitchell and Graziano, 2006; Sleister, 2007; Palombi and Jagger, 2008 are just a few examples).

In this report, I describe a semester-long laboratory project, primarily targeted for upper-level undergraduates who are biology or biochemistry majors who most typically have 
plans to perform laboratory research as technicians or graduate students or to enter professional schools. As would be expected with any laboratory course in molecular biology, two of my objectives are that students successfully perform the basic methods of this highly technical discipline (isolation of genomic and plasmid DNAs, restriction enzyme digestions and mapping, subcloning with ampicillin/X-gal selection, labeling DNA, agarose and polyacrylamide gel electrophoresis, and Southern hybridization) and learn the safest use of basic molecular laboratory instruments and reagents. Another goal is that this project not only cover these methods but also help students learn how to apply the techniques in a series of smaller experiments to obtain results whose analysis and interpretation help reach a broader scientific goal, in this case, the location and preliminary mapping of the dusky gene in Drosophila melanogaster by restriction fragment length polymorphism (RFLP) analysis. Furthermore, as is typical of a real-life research laboratory, I expect the students to perform more than one task in the same laboratory period: while a gel is undergoing electrophoresis, enzyme digests are being set up, for example. Final objectives are that performing these techniques toward a single scientific goal will help maintain the students' interest and yield results that provide enough material for each student to write a more realistic scientific paper that will challenge his or her analytical and interpretive skills.

My goal for this report is to describe a lab project that an instructor will be able to implement even if the class is large (24 students), with students diverse in academic achievement, lab experience, or interest in the material. This project should be doable regardless of limited availability of class time, financial resources, and technical help. As mentioned above, this project should yield at least some interpretable results so that by the end of the semester each student can write a full-length scientific report, especially important for courses that require a writing component. Though I designed this project to be completed in 12 3-h laboratory periods, it could easily be modified to require fewer or more laboratory meetings. The most appropriate student audience has had a course in genetics and previous training in basic laboratory methods, such as the use of balances, $\mathrm{pH}$ meters, glass pipettes, sterile technique, and so forth; however, if students are less prepared, an extra laboratory period could perhaps be devoted to training in these areas, and students could review the relevant points of genetics on their own time.

There are several reasons why the dusky $(d y)$ gene of D. melanogaster is used for this project. Though there are many historical and recent articles describing dusky and this $X$-linked gene's possible functions in controlling cell size (Dobzhansky, 1929; Dorn and Burdick, 1962; Newby et al., 1991; DiBartolomeis et al., 2002), it has not been extensively studied, so students will not easily find answers to experimental questions by looking them up online or by a trip to the library. This project requires the isolation of genomic DNA, and D. melanogaster is practical for this endeavor: Numerous flies are easy and inexpensive to rear, collect, and store for years at $-75^{\circ} \mathrm{C}$. Fruit flies are not hosts to any human pathogens, so they require no special permission to share them with members of the scientific and teaching communities, and no special care or government oversight is required in working with them in the teaching lab. Also, students are not usually morally opposed to crushing fruit flies. Besides the wild-type strain (Canton S), one mutant strain of D. melanogaster is required for this project, $d u s k y^{73}\left(d y^{73}\right)$, first isolated by Green (1975). This strain carries $d y^{73}$, a mutant allele of the $d y$ gene that was caused by a spontaneous insertion of a transposon (Newby et al., 1991; Lindsley and Zimm, 1992; DiBartolomeis et al., 2002; DiBartolomeis, unpublished results). This insertion of foreign material makes this the ideal mutant allele for this project because students are able to use RFLPs to map the location of the insertion site in the $d y^{73}$ mutant, so they can predict the location of the wild-type $d y$ gene, and they can characterize the transposable element by locating its restriction enzyme sites and estimating its size.

\section{EXPERIMENTAL OUTLINE (SCHEDULE) OF STUDENT ACTIVITY}

This project was designed for $12 \mathrm{wk}$ of laboratories that each meet once a week for $3 \mathrm{~h}$; recently, however, two of the lab exercises have been combined, so the project could be completed in 11 wk. Please see the Results and Discussion for possible modifications that could reduce the required number of lab weeks even further. Each lab period, before the students begin their lab work, I discuss the lab with the students, describing how it fits into the overall project, the protocols they will follow, and any new reagents or equipment they will be using. This introduction takes about 30-40 min. Since laboratory space is limited to 24 students, this project is designed for a maximum of six groups with four students per group; however, as few as five groups and as few as two students in a group have completed the project. Each student is given a laboratory manual with about 50 pages of step-by-step instructions for the project as well as a summary flowchart of the project (Figure 1), which emphasizes the multitask nature of most of the lab exercises. The manual also contains several appendices that include basic methodology (e.g., phenol/chloroform extractions), how to write a scientific paper, primers on RFLP mapping and laboratory safety, and other useful information. A list of the lab meetings follows:

- Week/Lab I Preparation of Solutions. Each student prepares his/her assigned solution to be used in the project by the whole class.

- Week/Lab II Isolation of Genomic DNA from Flies. Working in pairs or individually, students prepare genomic DNA from Canton $S$ or $d y^{73}$ frozen flies.

- Week/Lab III Quantification of Genomic DNA and Digestion of Plasmids. Students quantify genomic DNA using gels, digest plasmid and vector DNAs, and prepare gels for next week.

- Week/Lab IV Isolation and Purification of DNA from Agarose and DNA Ligation. Student groups gel purify the 2.6-kb fragment of wild-type DNA from previous plasmid digests and set up ligation reactions.

- Week/Lab V Transformation of Bacterial Cells and Restriction Digestion of Genomic DNA. Students transform Escherichia coli with ligation reactions and digest genomic DNA for Southerns. 


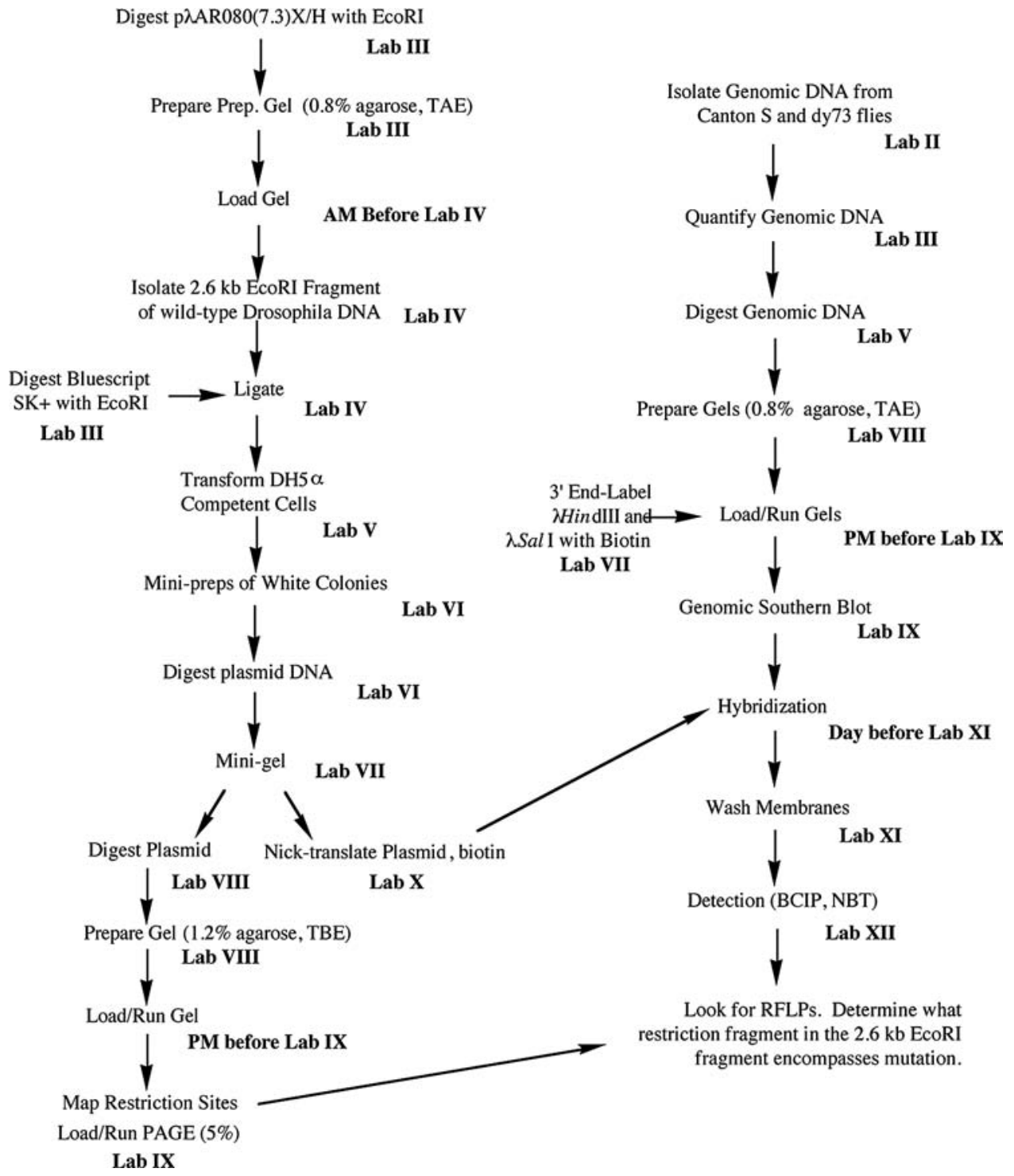

Figure 1. Flowchart showing overall plan of 12-wk project. The project to locate the dusky gene in D. melanogaster is carried out in two concurrent parts. The left side of the flowchart lists steps to subclone and map a genomic fragment to be used as a Southern hybridization probe to digested genomic DNA from wild-type and $d u s k y^{73}\left(d y^{73}\right)$ flies (right side of the flowchart). The two parts converge by lab XI.

- Week/Lab VI Mini Preparation of Plasmid DNA. Students isolate and EcoRI-digest plasmid DNA from overnight cultures of white colonies of transformed bacteria.

- Week/Lab VII Minigel Electrophoresis of Plasmid Digests and 3' End Labeling of Lambda Standard. Each student confirms that his or her plasmid has the $2.6-\mathrm{kb}$ insert, and each group prepares a lambda DNA HindIII and SalI-cut standard by labeling its $3^{\prime}$ ends with biotin.

- Week/Lab VIII Plasmid Mapping Digestions and Agarose Gel Preparations. Two sets of plasmid mapping digests are prepared by the class, and large agarose gels are prepared for next week. Mapping digests may be performed with tasks from lab VII to combine the two labs (with gels prepared during the week outside of class).
- Week/Lab IX Gel Electrophoresis and Southern Blotting. Genomic DNA and mapping digests are separated overnight through large gels, and genomic DNA is blotted in class the next day.

- Week/Lab X Biotin Labeling of DNA by Nick Translation. Each student group prepares nick-translated probes for genomic Southern hybridizations.

- Week/Lab XI Southern Hybridization. Each student group prehybridizes and hybridizes its Southern blot with the probe made the week before and then washes the blot during class.

- Week/Lab XII Detection of Biotinylated Probe. Each group detects the biotinylated probe using streptavidinalkaline phosphatase conjugate (SA-AP), nitro blue 
tetrazolium (NBT), and 5-bromo-4-chloro-3-indolyl phosphate (BCIP).

The Materials and Methods is an accounting of how the project was performed in the past several years-no major modification has been made since then. For a more detailed account of the Materials and Methods, especially directed to laboratory instructors, or for the course's lab manual, readers are invited to contact me for electronic copies (see Accessing Materials below).

\section{MATERIALS AND METHODS}

\section{Materials}

Most stock solutions were prepared by the students in week/lab I using water $\left(\mathrm{ddH}_{2} \mathrm{O}\right)$ purified through a Nanopure system. Both strains of D. melanogaster used in this investigation, Canton $S$ and $d u s k y\left(d y^{73}\right)$, were originally obtained from F.R. Jackson (now at Tufts University School of Medicine in Boston, MA) and have been maintained in the author's laboratory for over 19 yr. Canton S (wild-type) and $d y^{73}$ (homozygous mutant) flies were reared in bottles containing instant medium (Carolina Biological Supply, Burlington, NC) at room temperature. Flies were anesthetized with $\mathrm{CO}_{2}$, poured into polypropylene tubes, frozen in dry ice, and stored for up to $3 \mathrm{yr}$ at $-75^{\circ} \mathrm{C}$.

Previously, a genomic library screen yielded a lambda phage clone encompassing the wild-type (Canton S) $d y$ region (10E1-2 of the $X$ chromosome) of D. melanogaster (DiBartolomeis et al., 2002). A 7.3-kb XhoI/HindIII-digested fragment (approximate size based on gel migration) of this clone was inserted into an XhoI/HindIII-digested pBluescript $\mathrm{SK}+$ plasmid vector (Stratagene, La Jolla, CA), and miniprep DNA of this plasmid construct, p $\lambda$ AR080(7.3)X/H, was used as the starting material for the laboratory project.

Most DNA modifying enzymes were purchased from New England Biolabs (Ipswich, MA) and used as directed except that restriction enzymes were used in approximately eightfold excess.

\section{Cloning and Mapping of Genomic DNA from the dy Region of Wild-Type D. melanogaster}

In week/lab III, each student group digested approximately $2 \mu \mathrm{g}$ of p $\lambda$ AR080(7.3)X/H miniprep DNA and approximately $1.2 \mu \mathrm{g}$ of pBluescript SK+ plasmid vector DNA with EcoRI. The completion of each reaction was confirmed by $1 \%$ agarose minigel electrophoresis (performed by the instructor).

The next week (lab IV), each group gel purified the $\sim 2.6-\mathrm{kb}$ fragment from the EcoRI-digested p $\lambda$ AR080(7.3)X/H plasmid DNAs that had been size separated through a midigel. A GeneClean kit (Bio 101, MP Biomedicals, Irvine, CA) was used by the students to purify the DNA fragments from the $0.8 \%$ agarose matrix according to the manufacturer's instructions. DNA was eluted from the glass beads twice in a total of $15 \mu \mathrm{l}$ of $\mathrm{ddH}_{2} \mathrm{O}$, and $2 \mu \mathrm{l}$ were subjected to gel electrophoresis to assess for quantity and correct size $(2.6 \mathrm{~kb})$ of the purified fragment. Each group combined $12 \mu \mathrm{l}$ of the eluted DNA with $0.1 \mu \mathrm{g}$ of EcoRI-digested pBluescript SK+ DNA (see above), 200 units of T4 DNA ligase, and buffer and then incubated the $15-\mu 1$ reaction overnight at $4^{\circ} \mathrm{C}$.
In week/lab V, students transformed 50- $\mu$ l aliquots of subcloning efficiency competent $\mathrm{DH} 5 \alpha$ E. coli cells (Invitrogen, Carlsbad, CA) following the manufacturer's instructions. Approximately one-third of each transformation reaction was spread on Luria-Bertani (LB)/ampicillin plates in the presence of X-gal and isopropyl $\beta$-D-1-thiogalactopyranoside and incubated overnight at $37^{\circ} \mathrm{C}$. Each ligation reaction was used for two separate transformation reactions.

Individual white colonies from the transformation plates were used to inoculate $2.5 \mathrm{ml}$ of LB containing $50 \mu \mathrm{g} / \mathrm{ml}$ ampicillin; these cultures were incubated overnight at $37^{\circ} \mathrm{C}$ shaking at $\sim 120 \mathrm{rpm}$. Approximately $1.2 \mathrm{ml}$ of each culture were used for plasmid isolation (week/lab VI) using the alkaline lysis miniprep method described by Maniatis et al. (1982). DNA pellets were resuspended in $50 \mu \mathrm{l}$ of TE containing $20 \mu \mathrm{g} / \mathrm{ml}$ RNase A. Three $\mu \mathrm{l}$ of each plasmid isolate were digested with EcoRI or BamHI to confirm the presence of the $2.6-\mathrm{kb}$ insert or determine the orientation of the insert, respectively, by mini-agarose gel electrophoresis. The EcoRI digests were analyzed by the students in week/lab VII.

In week/lab VIII (which was done in combination with lab VII), half of the students performed mapping digests on the plasmid DNAs with the subcloned 2.6-kb insert in one orientation, and the other half digested plasmid DNA with the insert in the other orientation using $7 \mu \mathrm{l}$ of miniprep plasmid DNA $(\sim 0.7 \mu \mathrm{g})$, EcoRI, BamHI, PstI, and/or EcoRV and a $150-\mathrm{mM} \mathrm{NaCl}$ restriction enzyme buffer. Each $30-\mu 1$ single or double digestion was incubated for $3 \mathrm{~h}$ at $37^{\circ} \mathrm{C}$ and terminated with the addition of $2 \mu \mathrm{l}$ of $0.5 \mathrm{M}$ EDTA.

The night before week/lab IX, approximately $20 \mu \mathrm{l}$ of each mapping digest were size separated through $1.2 \%$ agarose in $1 \times \mathrm{TAE}$ at $25 \mathrm{~V}$ for about $14 \mathrm{~h}$ alongside appropriate size markers. During lab IX, the remainder of the mapping digests were separated by 5\% (29:1) polyacrylamide gel electrophoresis in $1 \times$ TBE (Sambrook et al., 1989) at $70 \mathrm{~V}$ for approximately $80 \mathrm{~min}$ in a Mini-PROTEAN II apparatus (Bio-Rad, Hercules, CA).

\section{Labeling of Probe and Size Marker DNA for Southern Blot}

In week/lab $X$, each student group biotinylated a $6-\mu 1$ $(\sim 0.6-\mu \mathrm{g})$ aliquot of pBluescript plasmid DNA containing the 2.6-kb insert of wild-type D. melanogaster genomic DNA using a nick translation kit (BioNick Labeling System, Invitrogen) according to the manufacturer's instructions. Reactions were purified using G-50 (medium) Sephadex columns. Each labeling reaction was used for the hybridization of one Southern blot (see below).

In week/lab VII, DNA fragments from a combination of HindIII-digested lambda DNA (250 ng) and SalI-digested lambda DNA (187 ng) were biotinylated at their 3' ends using 2.5 units of the Klenow (large) fragment of E. coli DNA polymerase I. Each $25-\mu 1$ reaction also contained $50 \mathrm{mM}$ Tris; $\mathrm{pH} 7.5 ; 10 \mathrm{mM} \mathrm{MgCl}$; $1 \mathrm{mM}$ dithiothreitol; $80 \mu \mathrm{M}$ each of dGTP, dTTP, and dCTP; and $16 \mu \mathrm{M}$ of biotin-14-dATP (Invitrogen) and was incubated at $37^{\circ} \mathrm{C}$ for $20 \mathrm{~min}$. The reaction was terminated with $2.5 \mu \mathrm{l}$ of $0.5 \mathrm{M}$ EDTA and purified over G-50 Sephadex. The labeled DNA was diluted to $\sim 5 \mathrm{ng} / \mu \mathrm{l}$ with TE and stored at $-20^{\circ} \mathrm{C}$. 


\section{Isolation and Digestion of Genomic DNA}

In week/lab II, approximately 500 frozen flies $(\sim 0.4$ g, equivalent to about $1 \mathrm{ml}$ of gently packed flies in a microfuge tube) were homogenized in a Dounce homogenizer in a nuclear isolation buffer according to DiBartolomeis et al. (2002). A total of six DNA preparations per fly strain were done by students working in pairs or as individuals. After being air dried, each DNA pellet was dissolved overnight at $4^{\circ} \mathrm{C}$ in $50 \mu \mathrm{l}$ of TE, $\mathrm{pH} 7.5$, and $20 \mu \mathrm{g} / \mathrm{ml}$ RNase A.

The approximate concentration and integrity of the genomic DNA was assessed in week/lab III by comparing the intensity of ethidium bromide (EtBr)-stained dilutions of the DNA against known amounts of EtBr-stained (uncut) lambda phage DNA on $1 \%$ agarose minigels. Concentrations ranged from 0.2 to $1 \mu \mathrm{g} / \mu \mathrm{l}$.

In week/lab V, $4 \mu \mathrm{g}$ of genomic DNA were single digested with EcoRI, EcoRV, XhoI, BamHI, or PstI or double digested with HindIII and XhoI, BamHI and SalI, or BamHI and EcoRV for about $6 \mathrm{~h}$ at $37^{\circ} \mathrm{C}$. Each $50-\mu 1$ reaction containing 30 units of each enzyme was terminated by the addition of $2.5 \mu \mathrm{l}$ of $0.5 \mathrm{M}$ EDTA.

\section{Genomic Southern Hybridization}

The night before week/lab IX, digested genomic DNAs were size separated through $0.8 \%$ agarose in $1 \times$ TAE (Sambrook et al., 1989) at $20 \mathrm{~V}$ for approximately $15 \mathrm{~h}$ alongside endlabeled (see above) and unlabeled lambda phage marker DNA.

During lab IX, student groups cut off the wells of each EtBr-stained gel and cut each gel in half. Gels were incubated for $30 \mathrm{~min}$ in denaturation buffer $(1.5 \mathrm{M} \mathrm{NaCl}, 0.5 \mathrm{M} \mathrm{NaOH})$ and then for another $30 \mathrm{~min}$ in neutralization buffer $(1.5 \mathrm{M}$ $\mathrm{NaCl}, 0.5 \mathrm{M}$ Tris, $\mathrm{pH}$ 7.5). Standard blotting apparatuses were assembled (see Sambrook et al., 1989; Ausubel et al., 2002) in $10 \times \operatorname{SSC}(1.5 \mathrm{M} \mathrm{NaCl}, 0.15 \mathrm{M} \mathrm{Na}$ citrate, $\mathrm{pH} 7)$ with overnight capillary transfer of DNA to positively charged or uncharged nylon membranes (Osmonics, Minnetonka, MN; distributed by Fisher Scientific, Pittsburgh, PA). Blots were baked at $80^{\circ} \mathrm{C}$ for $2 \mathrm{~h}$.

The night before week/lab XI, each group wetted its membrane in $\mathrm{ddH}_{2} \mathrm{O}$ and placed it in a plastic sealable bag with $\sim 0.2 \mathrm{ml} / \mathrm{cm}^{2}$ of prehybridization buffer containing $5 \times$ Denhardt's solution (Sambrook et al., 1989), $1 \mathrm{M} \mathrm{NaCl}, 1 \%$ SDS, and $0.1 \mathrm{mg} / \mathrm{ml}$ heat-denatured sheared herring sperm DNA (Promega, Madison, WI). Membranes were prehybridized for at least $1 \mathrm{~h}$ at $60^{\circ} \mathrm{C}$ with gentle agitation in a hybridization water bath (Stovall Life Science, Greensboro, NC). Nicktranslated probe DNA (see above) was boiled for $10 \mathrm{~min}$ and added to the prehybridization solution. Each bag was resealed, and hybridization occurred overnight (about $20 \mathrm{~h}$ ) with gentle agitation at $60^{\circ} \mathrm{C}$.

The next day, membranes were washed three times for 5 min per wash in $\sim 2 \mathrm{ml} / \mathrm{cm}^{2}$ of $1 \times$ SSC and $0.5 \%$ SDS at room temperature with agitation and then twice in $\sim 3 \mathrm{ml} / \mathrm{cm}^{2}$ of $0.1 \times$ SSC and $0.5 \%$ SDS with gentle agitation at $60^{\circ} \mathrm{C}$ for $30 \mathrm{~min}$ per wash.

Detection of the biotinylated probe on each blot (week/lab XII) began with a brief wash of each membrane in $0.1 \mathrm{M}$ Tris, $\mathrm{pH} 7.5$, and $0.15 \mathrm{M} \mathrm{NaCl}$ (buffer 1) before it was blocked for $35 \mathrm{~min}$ at $65^{\circ} \mathrm{C}$ with gentle agitation in $\sim 0.13 \mathrm{ml} / \mathrm{cm}^{2} 3 \%$ bovine serum albumin in buffer 1 (buffer 2; preheated at $65^{\circ} \mathrm{C}$ for $1 \mathrm{~h}$ ). Each blot was incubated in $\sim 0.1 \mathrm{ml} / \mathrm{cm}^{2}$ of a $1: 1000$ dilution of SA-AP conjugate (Invitrogen) in buffer 1 at room temperature for $10 \mathrm{~min}$ with gentle agitation. Blots were then washed twice in $\sim 3 \mathrm{ml} / \mathrm{cm}^{2}$ of buffer 1 for 15 min per wash with gentle agitation at room temperature and then for another $10 \mathrm{~min}$ in $0.1 \mathrm{M}$ Tris, $\mathrm{pH} 9.5,0.1 \mathrm{M} \mathrm{NaCl}$, and $50 \mathrm{mM}$ $\mathrm{MgCl}_{2}$ (buffer 3). For each blot, a dye solution $\left(\sim 0.13 \mathrm{ml} / \mathrm{cm}^{2}\right)$ was prepared by each group containing $0.3 \mathrm{mg} / \mathrm{ml} \mathrm{NBT} \mathrm{(In-}$ vitrogen) and $0.15 \mathrm{mg} / \mathrm{ml} \mathrm{BCIP} \mathrm{(Invitrogen)} \mathrm{in} \mathrm{buffer} \mathrm{3.} \mathrm{Each}$ blot was sealed in a heat-sealable bag with the dye solution; stored at room temperature in the dark for typically $50 \mathrm{~min}$ to $2 \mathrm{~h}$; and then incubated in $20 \mathrm{mM}$ Tris, $\mathrm{pH} 7.5$, and $1 \mathrm{mM}$ EDTA for $5 \mathrm{~min}$ at room temperature to terminate the development. Blots were dried before being photographed.

\section{Assessment of Learning Outcomes}

In each of the three fall semesters from 2005 through 2007, preand postquizzes were administered anonymously during the first laboratory meeting and the last laboratory meeting, respectively (Supplemental Material). Since no prequiz was administered to the 2008 students, only comments and not numerical results from these students were used in this report. Both quizzes asked the same 10 multiple-choice questions, which tested the students' knowledge of molecular tools and reagents (i.e., micropipettors, gel electrophoresis, EtBr), conversions (i.e., metric system, dilution of stock buffer), data analysis and interpretation (e.g., Southern hybridization, standard curves), and knowledge of RFLPs. Each of the 10 questions had a single correct choice and four incorrect choices. Students were asked to skip the question if they had no idea of the answer. Additionally, each quiz contained three survey questions that assessed the students' confidence in their molecular skills and lab skills in general and their plans to make careers of research in molecular biology. The postquiz also surveyed the students about their feelings of safety in the lab during the semester. The four survey questions were evaluated and quantified on a Likert scale $(1=$ strongly agree through $5=$ strongly disagree). The postquiz included two sets of questions that surveyed the students' perceptions of how difficult or interesting they found specific labs/techniques and the lab manual to be, again using a ranked evaluation ( $1=$ very easy or not interesting through $5=$ too difficult or very interesting). Students also responded with opinions about two RNA isolation labs at the end of the semester, which were not part of the 12-wk project; therefore, assessment scores for this set of labs are not included. Finally, the postquiz ended with questions that invited commentary about what interested or lacked interest for the students and about the laboratory in general and the laboratory manual.

Significance of differences between the three semesters of pre- and postquiz scores (correct answers and no answers) were determined by two-tailed, unpaired Student's $t$ tests (www.physics.csbsju.edu/stats/t-test.html). The number of students contributing to prequiz questions was 54; however, because of student withdrawals the total number of students who contributed to the postquiz was 51 .

Recent comments from two out of three former students (R.S. and M.Z.) who had written thank-you notes soon after their graduation from Millersville University were solicited. The other former student's (D.B.) comments were received unsolicited as a written thank-you note after a successful job search. 


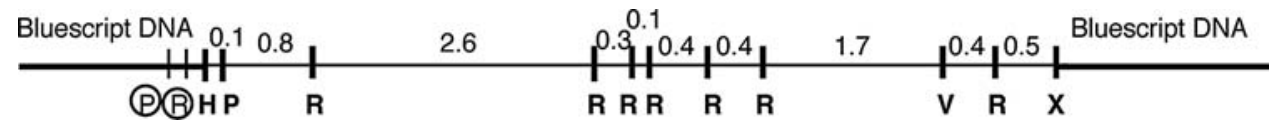

Figure 2. Restriction enzyme map of a 7.3-kb wild-type D. melanogaster fragment cloned into pBluescript SK+ (bold line). This plasmid DNA is the starting material from which the 2.6-kb EcoRI (R)-digested fragment is purified and subcloned to be mapped and used as a probe to detect RFLPs between digested wild-type and $d y^{73}$ genomic DNAs. This exact map is available to the students in the laboratory manual. Mapping sites to the 2.6-kb fragment will complete the map for PstI (P), EcoRV (V), and BamHI (B). There are no internal HindIII (H) or XhoI (X) sites, and circled $R$ and $P$ sites are in the vector's polylinker. Sizes are in kilobases $(\mathrm{kb})$.

\section{RESULTS AND DISCUSSION}

The series of experiments performed in this project yields results that ultimately allow students to identify the molecular location of dusky, a gene involved in controlling wing cell size in D. melanogaster (Newby et al., 1991). The gene is located by positional mapping using the detection of RFLPs between genomic DNAs of the wild type and $d u s k y^{73}\left(d y^{73}\right)$, a mutant caused by a transposable insertion. Classical genetics and cytology mapped the $d y$ gene to region 10E1-2 of the X chromosome (Dorn and Burdick, 1962; Lefevre, 1981). From this region, a 7.3-kb cloned fragment of a previously isolated library clone from a genomic walk of Canton S DNA is used as the starting material for this project (Figure 2). This fragment was chosen because it had previously been shown by RFLP analysis to encompass the insertion site of the transposon in the $d y^{73}$ genome (DiBartolomeis et al., 2002); since the transposon presumably disrupted the $d y$ gene to cause the mutant $d y$ phenotype, identifying the precise location of the transposon also provides the likely location of the dy gene.

\section{Subcloning a Smaller Genomic Fragment}

In this project, students follow some of the actual steps used to clone the $d y$ gene (DiBartolomeis et al., 2002), by first subcloning a smaller piece of the 7.3-kb genomic fragment into a commonly used vector, pBluescript. If part or all of the $d y$ gene was in this fragment, an RFLP analysis using this smaller fragment as a probe for Southern hybridization would result in detection of the insertion site of the transposon. A $2.6-\mathrm{kb}$ EcoRI-digested fragment of the $7.3-\mathrm{kb}$ region was the first fragment chosen to be subcloned and tested via RFLP analysis because it is the largest fragment produced by EcoRI digestion and thus had the greatest chance of encompassing the DNA disrupted by the transposon. The digestions of the plasmid and the vector are, for at least some students, the first digestions they ever set up. Because the linearized vector is not gel purified, it is important to ensure by checking the digests that the vector digestions contain only linearized molecules-any remaining uncut supercoiled vector molecules would transform competent $E$. coli with too great an efficiency, making transformation with the recombinant plasmid less likely.

The subcloning of this fragment requires that students learn the difference between analytical and preparative gels, including limiting ultraviolet light exposure to the DNA in the preparative gel. They learn a method of purifying fragments from agarose - the glass bead method in this case, though the instructor may modify the protocol to use one of the many alternatives. Also, in this portion of the project, students use the theoretical knowledge about cloning taught to them in the lecture portion of the course to select for and identify transformed bacteria hosting recombinant plasmids using ampicillin and blue/white selection through $\beta$-galactosidase expression. Since the students do not dephosphorylate their EcoRI-digested vectors, they witness the greater likelihood of the intramolecular ligation (vector recircularizing) versus the intermolecular ligation (vector ligating to fragment) by visualizing the greater number of blue versus white transformants. Finally, the students learn how to perform a "miniprep" of plasmid DNA, one of the staple laboratory protocols in molecular biology.

If necessary, eliminating the subcloning of the 2.6-kb fragment would allow an instructor to abridge this project by three or four laboratory periods. The instructor can start the project with plasmid DNA containing the already subcloned EcoRI-digested fragment; alternatively, so that students still perform the miniprep procedure, the starting material can be the $E$. coli cells that host the plasmid.

\section{Restriction Digest Mapping}

For interpretation of the RFLP results, the students must map restriction enzyme cleavage sites to this $2.6-\mathrm{kb}$ region and, therefore, to the genomic DNA it represents. To perform the mapping digests, the students work in large groups to make master mixes of plasmid DNA and buffer, which are dispensed into tubes, so that individual students add the appropriate enzyme(s) to their digests. Because students produce clones with the 2.6-kb insert in both directions, there are two sets of mapping digests made and separated through the same large agarose gel (Figure 3), a total of 10 digests for each orientation of the insert. The digital photograph (such as seen in Figure 3) is made available on the Internet. The entire plasmid with the $2.6-\mathrm{kb}$ fragment inserted in the EcoRI site of the vector's polylinker, as well as the vector itself, is digested and mapped. Half of the students produce a map of the insert from the digests on the left of the gel, and the other half of the class map the other orientation with the other half of the gel.

In one orientation, it is not possible to map one of the insert's BamHI sites unambiguously; however, the clever student could study the digest results of the plasmid carrying the insert in the opposite orientation to definitively locate the site. Though having plasmids with inserts with two orientations may seem to invite confusion, it can be used as a teaching opportunity for more in-depth understanding of mapping and cloning.

Agarose is limited at resolving small $(<600 \mathrm{bp})$ fragments that are close in size, so about a third of each mapping digest is size separated through polyacrylamide minigels, one gel for each orientation (Figure 4 and unpublished data). Digital photographs of these gels are made available to the students 


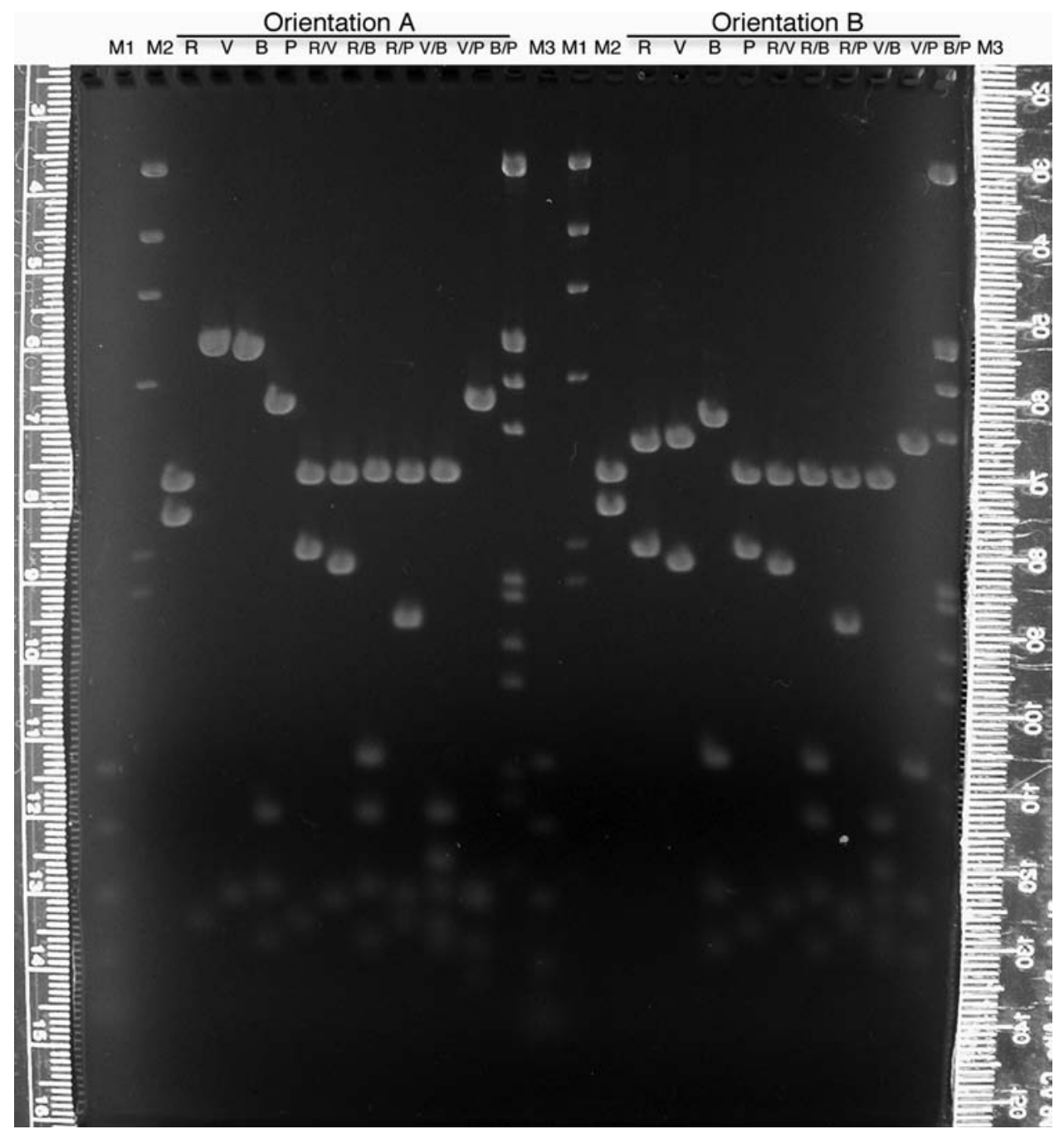

Figure 3. Mapping gel (1.2\% agarose, $1 \times \mathrm{TAE})$ separating restriction enzyme fragments of plasmid DNA containing a 2.6-kb insert of wildtype D. melanogaster DNA from the dusky area of the genome. Students (Fall 2007) used the enzymes EcoRI (R), EcoRV (V), BamHI (B), and PstI $(\mathrm{P})$ individually or in pairs to digest plasmid DNAs containing the insert in both orientations (A or B). After staining with ethidium bromide and destaining in $1 \times \mathrm{TAE}$, the gel was visualized and digitally photographed (Nikon CoolPix995 camera) on an ultraviolet transilluminator (Fotodyne, Hartland, WI). Lambda DNA digested with HindIII (M2) or double digested with HindIII and EcoRI (M3) and a polymerase chain reaction standard (M1; Promega) were used as size markers. The rulers pictured were used to measure migration of the DNA fragments, and each student constructed a standard curve from which the sizes of the DNA fragments were extrapolated. The entire photograph (which is what was placed online for student use) was enhanced (contrast and brightness) using Adobe Photoshop.

on the Internet and with class handouts. As expected, the polyacrylamide gels do resolve different-sized fragments that migrate as one band on the agarose gel (e.g., Figure 4 and Figure 3, B/P digest for orientation A); however, as warned by Sambrook et al. (1989), the polyacrylamide also causes one of the smaller fragments to migrate relatively faster than its size should allow (compare Figure 3, V/P digest, with Figure $4, \mathrm{~V} / \mathrm{P}$ digest). Such an inconsistency in migration is unusual, but it can be used to teach a valuable lesson to the students: They should check data from different protocols for consistency, and if aberrancy is found, they should pursue a logical explanation and not just assume that they must have done something wrong.

Sometimes, a few of the mapping digests do not go to completion, resulting in lanes with extra bands that are larger than expected and usually with low intensity. Though this situation makes mapping somewhat more challenging for the students, it is a good opportunity to teach students how to recognize "partials" and possibly to use them to their mapping advantage-if the size of a partially digested fragment indicates the definitive juxtaposition of two smaller fragments, for example.

\section{Preparation and Electrophoresis of Genomic DNA}

The plasmid containing the $2.6-\mathrm{kb}$ fragment from the wildtype genome is used as a probe in Southern hybridizations to restriction enzyme-digested genomic DNAs from the wild type, Canton $S$, and the mutant, $d y^{73}$. This is the first opportunity for the students to isolate DNA in this laboratory course. 
$M \quad R \quad B \quad B \quad P R / N R / B R / P$ V/B V/P B/P $M$

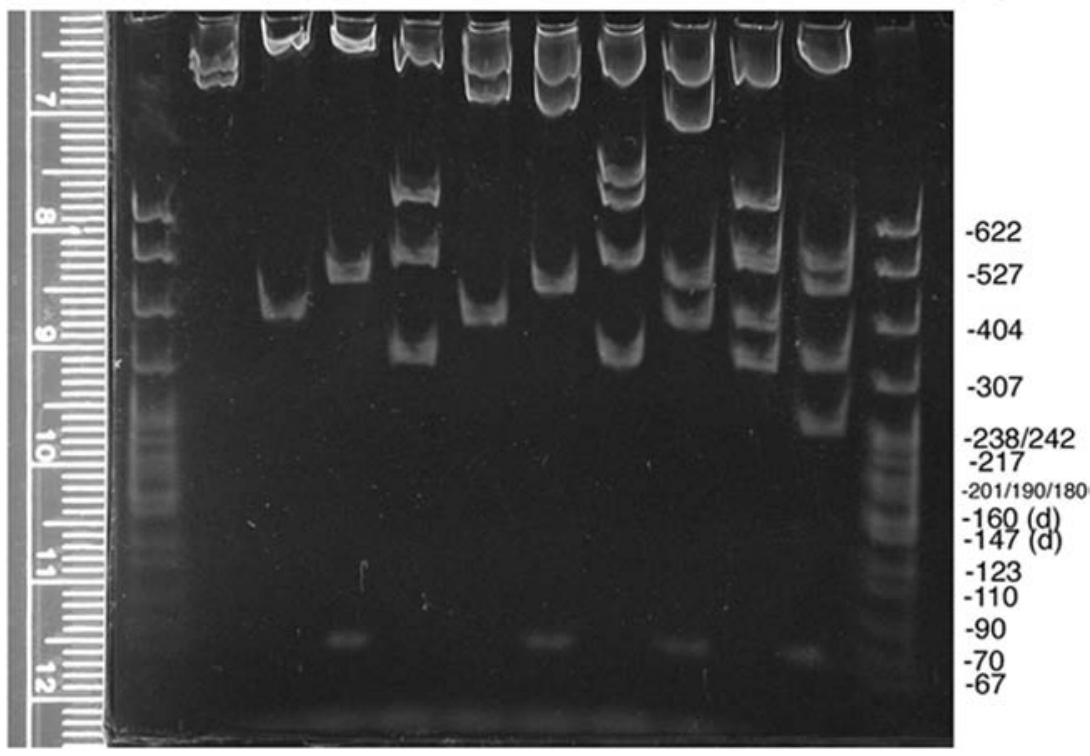

Figure 4. Mapping gel (5\% 29:1 polyacrylamide, $1 \times \mathrm{TBE})$ separating restriction enzyme fragments of plasmid DNA containing a $2.6-\mathrm{kb}$ insert of wild-type $D$. melanogaster DNA from the $d u s k y$ area of the genome. Aliquots of the same digests separated on the agarose gel (Figure 3) were separated by nondenaturing polyacrylamide minigel electrophoresis. Only the gel with digests of the plasmid with the insert with orientation A is shown. DNA in these 1-mm-thick gels was stained with ethidium bromide, destained in $1 \times \mathrm{TBE}$, and visualized and digitally photographed as described above (Figure 3). Migration of standard marker fragments (M; MspIdigested pBR322) was measured (using the ruler pictured or an external one), and each student constructed a standard curve for the gel. The refined resolution and extrapolated sizes of the small fragments ( $<600 \mathrm{bp}$ ) confirmed fragments detected on the agarose gel as well as helped detect doublets and very small fragments such as the BamHI-digested fragments at approximately $70 \mathrm{bp}$. This photograph (made available online for student use) was enhanced (contrast and brightness) using Adobe Photoshop.
The high-molecular-weight DNA, once precipitated, is easy to visualize as the classic "white, thready" material that provides a satisfying and encouraging end to this early lab. A few weeks later, when the students isolate plasmid DNA, it is valuable for them to compare the two DNA isolation protocols, particularly where the small size of the plasmids allows for vortexing of organic extractions and ethanol precipitations as opposed to the high-molecular-weight genomic DNA, which requires inverting at these mixing steps.

Students quantify their DNAs using the intensity of EtBr staining; however, other instructors may prefer to use a UV spectrophotometer (at $260 \mathrm{~nm}$ ) or any one of many kits that are designed to quantify DNA (usually with a fluorometer). The quantifying gels were also used to confirm the integrity of the DNA: high molecular weight and little, if any, RNA contamination.

Each student is assigned at least one enzyme digest of his or her genomic DNA. The students perform eight different genomic DNA digests for each strain (Canton $S$ and $d y^{73}$ ). All but one enzyme digest (BamHI/EcoRV) is duplicated, so there are 30 digests altogether. Reactions are separated in pairs, with each pair composed of Canton S DNA and $d y^{73}$ DNA digested with the same enzyme and loaded adjacently so that RFLPs can be easily identified (Figure 5). The instructor may choose to reduce or increase the number of digests performed on the genomic DNA or change the combinations of enzymes used, but experience has proven the duplication of the digests to be quite helpful when blots, probes, or digests produce suboptimal results. It is also helpful for the students or instructor to confirm digestion and quantity of the genomic DNA in the digests by checking a small aliquot of each digest on a mini-agarose gel. Out of the 30 digests performed by the students each year, usually a few need to be repeated because they have too little DNA or the DNA is not completely digested.

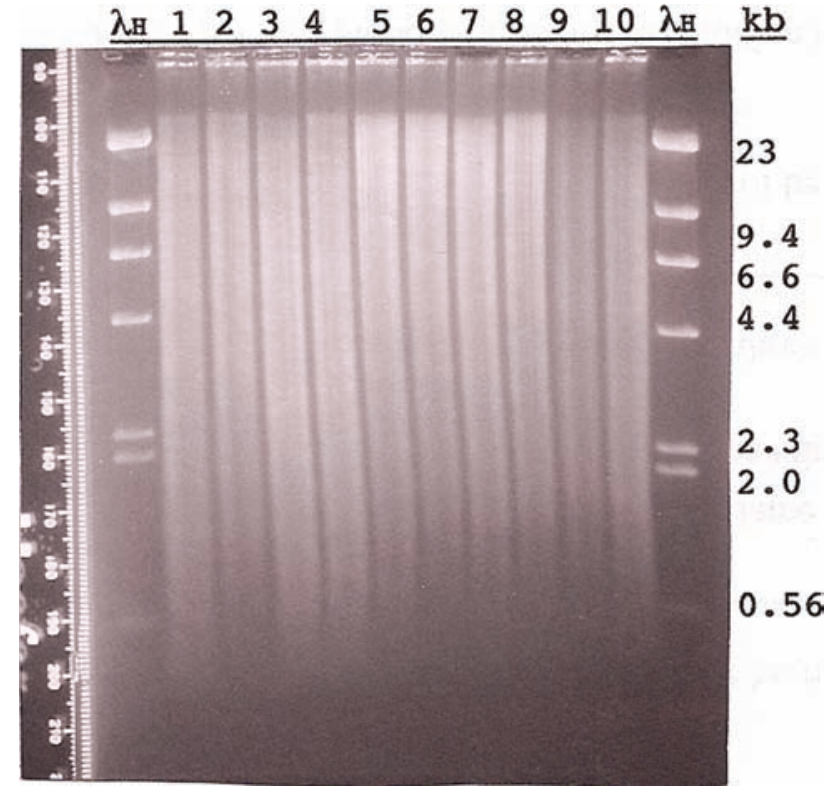

Figure 5. Agarose gel (Fall 2009) of Canton S (CS) and $d u s k y^{73}\left(d y^{73}\right)$ genomic DNA digested with different restriction enzymes. Approximately $4 \mu \mathrm{g}$ of CS DNA (lanes $1,3,5,7$, and 9) and $4 \mu \mathrm{g}$ of $d y^{73}$ DNA (lanes 2, 4, 6, 8, and 10) were digested with EcoRI (lanes 1 and 2), PstI (lanes 3 and 4), XhoI (lanes 5 and 6), BamHI (lanes 7 and 8), or BamHI and SalI (double digest; lanes 9 and 10) and size separated overnight through $0.8 \%$ agarose $(1 \times \mathrm{TAE})$. Standard marker on the outside lanes is HindIII-digested lambda DNA $(\lambda \mathrm{H} ; 1.25 \mu \mathrm{g})$. The gel was stained with EtBr, destained in $1 \times$ TAE, and visualized and photographed (Polaroid, 667 film) on an ultraviolet transilluminator. The Polaroid print was digitally scanned and enhanced by Photoshop. Before being blotted, the gel was cut in two (between lanes 4 and 5), and each part was given to two of the six student groups for blotting. The Southern hybridizations of these blots are shown together in Figure 6. 


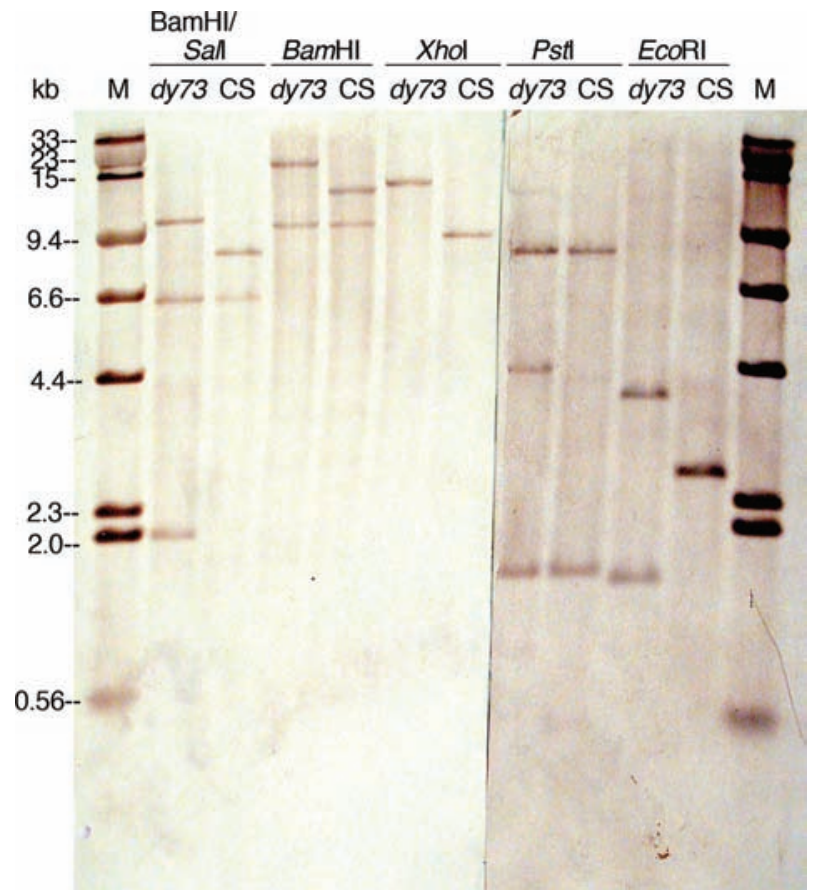

Figure 6. Southern hybridizations showing RFLPs between restriction enzyme-digested Canton S (CS) and $d u s k y^{73}\left(d y^{73}\right)$ genomic DNAs. The gel shown in Figure 5 was sliced in two and blotted onto nylon membranes, hybridized with biotinylated plasmids containing a 2.6-kb EcoRI-digested fragment of the CS genome, and detected with streptavidin-alkaline phosphatase conjugate, BCIP, and NBT. The blots (mirror images of the gels due to the blotting procedure) were paired up and digitally photographed (Nikon Coolpix995 camera). This photograph (which was posted online for student use) was enhanced (autolevels, contrast, brightness, and annotation) with Photoshop. The standard marker (M) is a mixture of biotinylated HindIIIdigested lambda DNA and SalI-digested lambda DNA that had been size separated and blotted with the 1.25- $\mu \mathrm{g}$ HindIII-digested lambda DNA visible on the EtBr-stained gel (Figure 5).

\section{Southern Blotting and Detection of Probe}

In this project, every effort is made to have each student work in as small a group that is practical for the particular procedure being done. With this in mind, each gel that is to be blotted is cut in half, resulting in six Southern blots. In a "real" lab, the gels would remain intact; however, splitting the gels allows up to only four students per group, greatly increasing the chance of hands-on experience for each student. Once the blots are hybridized and their probes detected, then the blots are paired to represent the full gels (Figure 6).

In the lecture portion of my course, the students learn about several different methods of labeling nucleic acids, including nick translation and $3^{\prime}$ end labeling via the "fill-in" technique using the Klenow fragment of E. coli DNA polymerase I. These two methods are used in this RFLP project, the former for uniformly labeling the Southern hybridization probes and the latter because it maintains the integrity of the DNA fragments, for producing prelabeled lambda DNA standards to be transferred to the Southern membrane. The biotinylated lambda standard serves not only as a molecular weight marker but also as a positive control for the detection of the Southern hybridization: If no bands are seen from the digested genomic DNA, but a lambda standard is detected, then the probe was likely not properly prepared or the hybridization was not performed correctly.

This project was developed in an environment in which most of the junior and senior undergraduates, like their graduate peers, live off campus; many students work or take a class in the evenings-some are parents and need to be home with their families. Hence, it is important that as much of the laboratory work as possible can be done within the 3-h scheduled lab period. The prehybridization and start of the hybridization of the blots with the nick-translated probes have to be done the afternoon/evening before the scheduled lab, however, so that the membranes can be washed in lab the next day. When given enough warning and chance to plan with their lab mates, it is rare that a student is not able to contribute to at least the prehybridization or the addition of the probe.

The procedures for washing the hybridized membranes and detection of the probe usually proceed smoothly. The students prepare their own wash buffers from stock solutions (made in lab I). The most stringent wash is with $0.1 \times$ SSC at $60^{\circ} \mathrm{C}$. Using a lower salt concentration or temperatures above $60^{\circ} \mathrm{C}$, perhaps to reduce background, has not been attempted. Washed blots are stored in plastic wrap until the next week when the biotinylated probe is detected using alkaline phosphatase-conjugated streptavidin. This procedure requires the preparation of four solutions, two of which can be made by students from stock reagents during the lab.

The detection of the probes (using NBT and BCIP) occurs with each membrane in a sealed bag. Depending on the strength of the probe, the particular digests blotted on the membrane, and the background of the detection, some blots are left to develop for as long as $2 \mathrm{~h}$, while others require less than $1 \mathrm{~h}$. By the time the detection solution is added, the $3-\mathrm{h}$ period is almost at its end. Before the students depart the lab, they see bands from the biotinylated lambda standards and, on some blots, the faint bands of the higher-molecular-weight RFLPs. Though many directions for colorimetric detection suggest photographing the blots while they are wet, smudgy background seems to decrease without a significant loss of contrast if the blots are dried before being photographed.

From the digital photographs of the blots, made available on the Internet (e.g., Figure 6) and the handouts of photocopies, students measure band migrations of the molecular weight lambda standards and the digested genomic DNA. Each student constructs three standard curves, one for each blot (now the size of the original gel since the six blots were matched in pairs), and calculates the band sizes in each lane of genomic DNA. Sizes for duplicate digests are averaged together. From these data, and the restriction enzyme map of the genome in the $d y$ region (Figure 2 supplemented by the students' map of the EcoRI-digested 2.6-kb insert), each student constructs a map of the wild-type genome from the $d y$ region that spans about $23 \mathrm{~kb}$. Using this map, and the size of the RFLPs in the $d y^{73}$ genome, the student can identify a putative location for the wild-type $d y$ gene by deducing where the transposable mutation occurred to create the $d y^{73}$ allele. For example, one student correctly reasoned in his report that “... the PstI digest revealed where the insertion insinuated itself. The two fragments found in the wild type digest were conserved in the mutant digest suggesting that neither was disturbed by the insertion. The mutation must occur, therefore, somewhere between the two outermost PstI sites found 
in the probe region" (L.B., 1997). Students use the Southern blot data to determine the size and a preliminary map of the transposon; explained another student, "I also hypothesize the transposon is about $5.6 \mathrm{~kb}$ in length. This was determined by averaging the RFLPs between the CS and $d y^{73}$ genomic DNAs digested with BamHI and XhoI. These were the two restriction enzymes that did not have a different number of fragments in their CS and $d y^{73}$ lanes, and therefore they were assumed to not have sites in the transposon" (M.L., 2006). Yet another student's report adds to this mapping strategy: "I knew that there was a SalI site within the transposon because there was an extra $d y^{73}$ fragment compared to CS for that digest" (K.R., 2007).

Though in their reports students are expected to discuss the accuracy and precision of their data, I evaluate the students on their analyses of their data-not how correct or accurate their maps are relative to previously published or unpublished data. Because each student constructs his or her own standard curves (by hand), and extrapolates fragment sizes from bands whose migrations he or she has manually measured, each student's results may differ slightly from mine or from those of the other students. Working manually, without the use of a computer, allows the student to understand the scientific foundation of the gel analysis software now available at many research institutions. An added benefit to manual analysis for me as a teacher is that I am assured that each student is performing his or her own work, since no two maps should be exactly the same.

The experiments for this project end with the RFLP analysis, but the project may be expanded by adding the experiments that would be done in the "real world" to confirm the molecular location of the dusky gene. For example, after the RFLP analysis described in this report, the smaller fragment identified to be the probable insertion site for the transposon would be used as a probe for more Southern hybridizations with wild-type and $d y^{73}$ DNA that would confirm the fragment as the transposon's insertion site. Second, the same fragment could be used as a probe for a northern hybridization or an RNase protection assay with RNA isolated from different developmental stages of wild-type and $d y^{73}$ flies to show that the fragment hybridizes to a transcript that is disrupted in the mutant. Instructors may want to expand the project to show that other mutant alleles of $d y$ (e.g., $d y^{1}$ ) are associated with RFLPs in the same region as those seen with $d y^{73}$. One student suggested "to continue the analysis [by] alter[ing] the same area of the genome disrupted by the insertion. If an alteration other than an insertion causes the same abnormal phenotype, it would indicate that we have located the correct area [for $d y]^{\prime \prime}$ (I.R., 2007).

\section{Assessment of Student Learning}

During the semester, the students' analytical and laboratory skills are assessed via questions derived from concepts and skills taught during the semester's labs but not using the same information or data from the laboratory project. These questions are administered as part of the take-home (open-book) and in-class (closed-book) lecture exams occurring throughout the semester. For example, in the first third of the course, questions are asked related to making solutions of specific concentrations from powder or stock solutions. In the middle of the semester, students are given a multipart question test- ing their strategies for mapping restriction enzyme sites to a cloned insert, something they will be required to do for the project. In the latter third of the semester, I give the students a problem with hypothetical RFLP results, which guides the students in a step-by-step procedure for characterizing the wild type and a mutant form of a gene. The mutant allele in this hypothetical case is also a result of a transposable insertion, so the students are able to practice characterizing an insertion as they will have to do for the lab project. How a student performs on these latter two questions will indicate to him or her and me whether further instruction is needed. Please see the Supplemental Material for examples of each of these three questions.

Students may assess their own learning during the semester by attempting the optional questions within and at the end of each laboratory exercise. These questions include "Where in the molecular suite are the scoopulas and weigh paper regularly located?" "What are the final concentrations of the buffer components in your restriction enzyme digests?" "Which of your ligation products would not rescue a transformed E. coli cell from death by ampicillin?" "Which would make a more effective probe for hybridization-a nicktranslated fragment or an end-labeled fragment-and why?" and "What are the genetic and phenotypic differences between Canton $S$ and $d y^{73}$ flies?" Questions such as these test a broad range of knowledge, including reading of the lab manual, laboratory skills, familiarity with locations of reagents and instruments in the lab, theoretical concepts, and strategies related to molecular techniques such as cloning.

To assess student learning from a before-and-after perspective in a way that could be quantified and controlled, I administered a pre- and a postquiz that were taken anonymously by the students at the beginning and the end of each of three semesters (Fall 2005-Fall 2007). The first 10 questions were multiple choice and tested the students' factual knowledge of laboratory techniques and skills (Figure 7 and Supplemental Material). The mean scores for correct answers show a significant $(p<0.0001)$ improvement: $57 \%$ for the prequiz versus $81 \%$ for the postquiz. Students also show a significant $(p<0.0001)$ increase in confidence in answering questions: Students had no idea of the answer $19 \%$ of the time on the prequiz, but when faced with the same questions at the end of the semester, on average only $2 \%$ of the questions were left unanswered.

Some questions showed more improvement than others. When answering questions about the use of $\mathrm{EtBr}$ and being able to recognize a Southern hybridization result to be an RFLP, students' scores increased from 61 to $98 \%$ (EtBr question) and 22 to $98 \%$ (defining RFLP question). Confidence levels in answering these two questions increased dramatically: The $28 \%$ (EtBr) and $63 \%$ (RFLP) of the students who could not answer the two questions in the prequiz felt confident enough in their knowledge to answer them in the postquiz. There were four multiple-choice questions that students had complete or almost complete confidence in answering even at the beginning of the semester: a conversion from kilobase to base pairs, the correct setting of a Pipetman P20 for a specific volume, extrapolating molecular weight from a standard curve, and a metric conversion from microliters to milliliters. These also happened to be the four questions that yielded the least improvement (10\% or less) for correct answers in the postquiz. Overconfidence may be an issue here: Since the 


\section{Prequiz and Postquiz Scores}

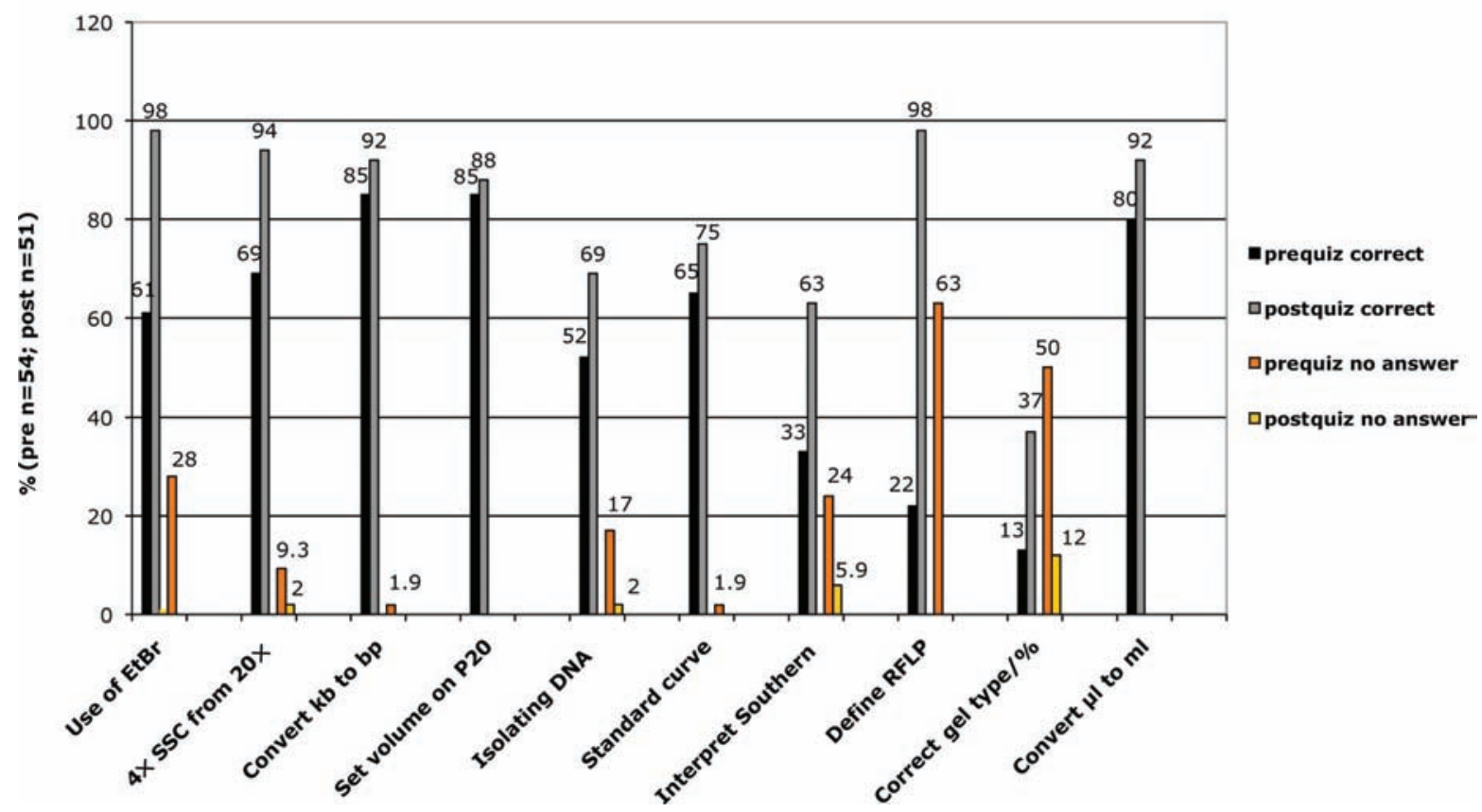

Figure 7. Students show improvement in answering multiple-choice questions about topics related to molecular biology and the laboratory project. Over three semesters (Fall 2005-Fall 2007), a prequiz and a postquiz administered anonymously to the students included the same 10 multiple-choice questions (key phrases are shown below the $x$-axis). The percentage of questions answered correctly in the postquiz (gray bars) was higher than that for the prequiz (black bars) for all 10 questions. Additionally, students were instructed to leave a question blank if they had no idea of the answer. The percentage of students leaving a question unanswered decreased on the postquiz (yellow bars) relative to that of the prequiz (orange bars).

conversion questions in particular are based on the metric system, with which students should be familiar from their freshman year, students may think that they have nothing to learn and, therefore, must be right. For example, in the comment section of the postquiz, one student wrote, "some things could have been explained in less depth, like how to pipette"; however, this student incorrectly answered the question about the Pipetman.

Of course, the context in which these assessment results were derived must be considered. For instance, students at this level are usually taking other courses, such as virology, biochemistry, and microbiology, with labs that employ related methodology. Perhaps some of their knowledge in molecular biology was gained from their experiences in these courses. Also, the point could be made that the students had seen these same questions 14 weeks before when they took the prequiz and they could have figured out and memorized the multiplechoice answers for the postquiz. This is unlikely since the students knew that the results of the quizzes did not impact their grades; furthermore, the postquiz answers do not display the consistent correctness that one might expect from such foreknowledge. Using different multiple-choice questions on the pre- and postquiz, on the other hand, could have caused other concerns, such as the potential for questions being easier or harder on the prequiz versus the postquiz, which could have increased the risk for biased results.

Typically, my final assessment of how well the students learned application of molecular concepts and techniques and interpretation of scientific data is the report that is due at the end of the semester. Some of the data interpretation, a figure of the wild-type map, part of the Materials and Methods, and the significance of the research (for the Introduction) are due 2 weeks earlier to assess each student's understanding of and accuracy in data analysis. If an instructor wanted to test the students' ability to apply their knowledge to a different problem, however, he or she could administer a final laboratory quiz that subjects the students to hypothetical RFLP results that issue from a wild-type and a mutant allele from a deletion or inversion, instead of a transposition. Will the students be able to map the location of missing or inverted DNA? If a deletion, will the students be able to determine the amount of DNA that was deleted? Could they reason what enzyme sites are eliminated from the deletion? Though a final exam such as this may test the student's ability to synthesize new data, it unfortunately does not test the student's ability to analyze the imperfect and somewhat ambiguous data collected from real gels and real blots. This final quiz could be made more challenging for graduate students by requiring each student to create the question itself, complete with the correct answer. In my experience, it is often more difficult for students to create good questions than it is just to answer those given by me.

In addition to assessing learning outcomes, the prequiz and the postquiz surveyed the students' opinions about their confidence, future plans in molecular biology, and skills in the lab. These three questions were answered on a Likert scale 


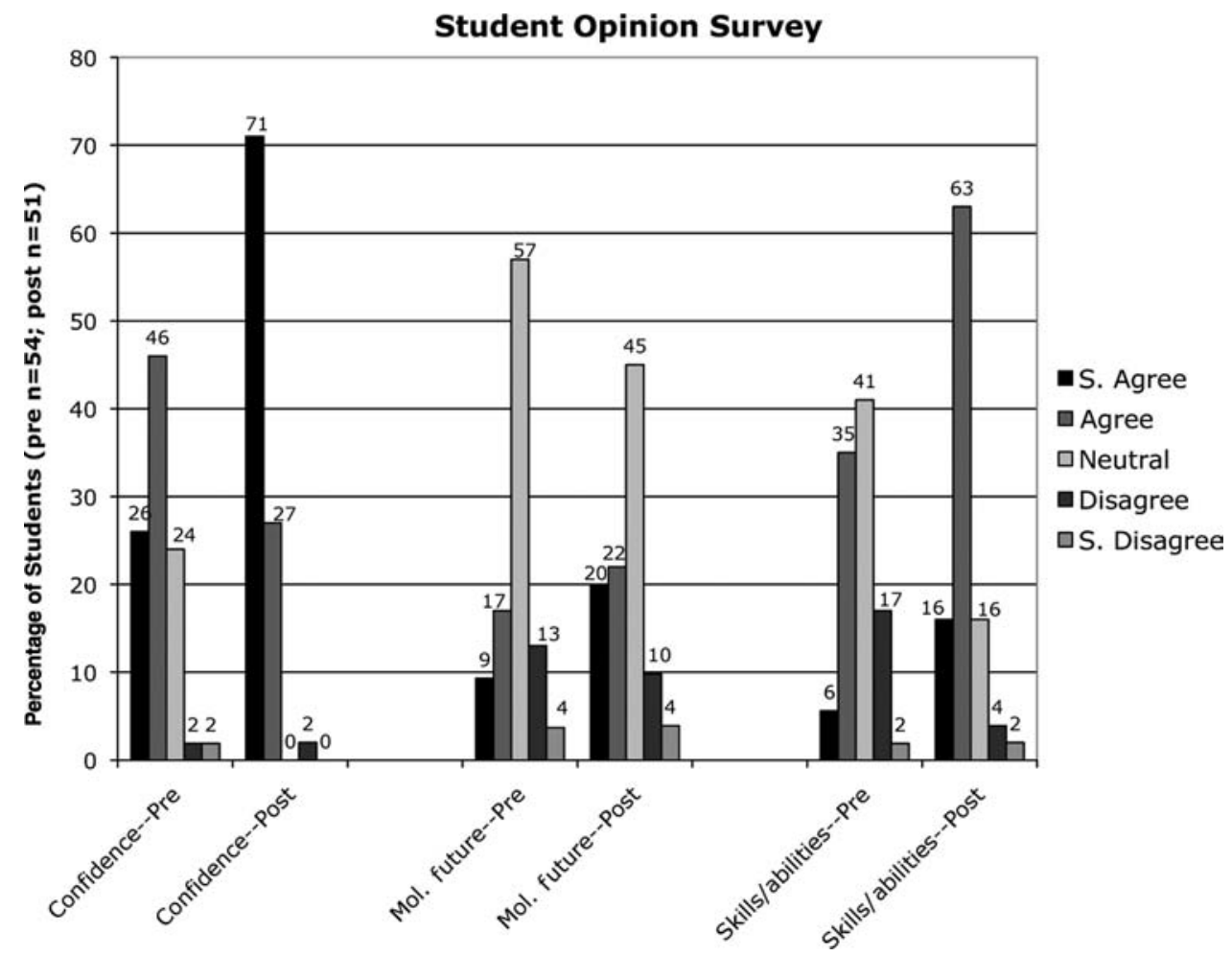

Figure 8. Responses to survey questions on the prequiz and postquiz indicate that the 12-wk laboratory project helped increase the students' confidence in the lab and their perception of their laboratory skills. At the end of the semester, a total of $98 \%$ of the students agreed or strongly agreed that they were more self-assured in the molecular biology lab, compared with the $72 \%$ of the students expressing the same confidence at the beginning of the semester. A similar question about the students having no concerns about their skills and abilities in the lab garnered a greater increase; $79 \%$ agreed or strongly agreed in the postquiz versus $41 \%$ agreeing or strongly agreeing on the prequiz. The data also show that $16 \%$ more students were interested in performing research in molecular biology in the future.

(strongly agree to strongly disagree; Figure 8 and Supplemental Material). The students' feelings of self-assurance in the lab at the beginning of the semester were already generally positive, with $72 \%$ of the students agreeing or strongly agreeing that they could handle themselves in a molecular lab; however, these feelings were almost unanimous by the end of the lab project $(98 \%$ placed themselves in one of the agreement categories-only 1 student out of 51 was in disagreement; Figure 8). There was also a marked increase in the students' perceptions of their abilities and skills. By the end of the project, $16 \%$ of the students strongly agreed and $63 \%$ agreed with the statement "I have no concerns about my skills and abilities in this lab"; at the beginning of the semester, these percentages were $6 \%$ and $35 \%$, respectively, representing a total increase for both rankings of $38 \%$. A more modest increase in agreement was seen, however, with the statement "Molecular biology research (in the lab) is what I want to do in the future." The students choosing either strongly agree or agree with this statement increased from $26 \%$ to $42 \%$, with most of that increase possibly derived from the students who originally answered with the middle ranking of neutral/ambiguous/not sure, which was $57 \%$ at the beginning of the semester and $45 \%$ at the end. That the number of students hoping for a future in molecular research is not greater at the end of the semester is somewhat expected. Though most of the students taking this course (BIOL 462, Molecular Biology) are biology major seniors in the molec- ular biology/biotechnology option (i.e., concentration), the curriculum of the molecular option is preferred for students who are interested in earning doctorates in medicine, dentistry, or veterinary science. It is unlikely that this course will change the minds of students bound for careers in these professions; whereas if students thought they wanted to be molecular biologists, this course, particularly the laboratory portion, can cause them to think twice. The lab gives students an appreciation of the attention to detail and the patience required to work with such small volumes and sizes. Some students find it too frustrating and move on to another subdiscipline in biology. To assess whether and in what direction students might be changing their minds about their careers in molecular biology, another question on the postquiz might be appropriate, such as "After taking this lab, my overall attitude toward following a research career in molecular biology is a) much more positive; b) more positive; c) unchanged; d) more negative; e) much more negative."

At the end of each semester, I wished to know both how difficult and how interesting the students thought the lab project and its accompanying lab manual to be (Figure 9 and Supplemental Material). Again, I asked for their perceptions using a Likert scale of rankings from very easy (point value of 1) to too difficult (point value of 5) and not interesting (point value of 1 ) to very interesting (point value of 5). Only the RFLP project was considered difficult (or too difficult) by a majority of the students $(56 \%)$. Their comments 


\section{Perceived Difficulty}

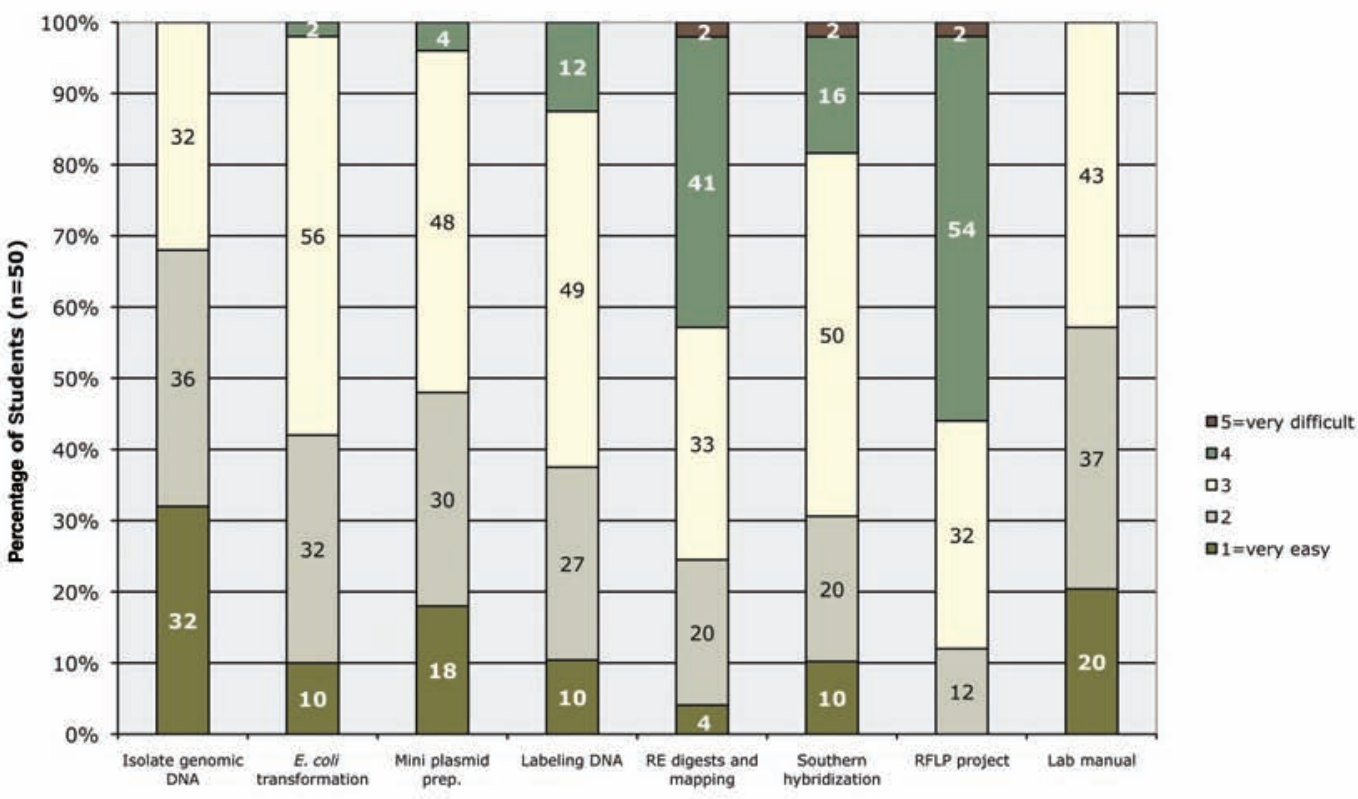

Perceived Interestingness

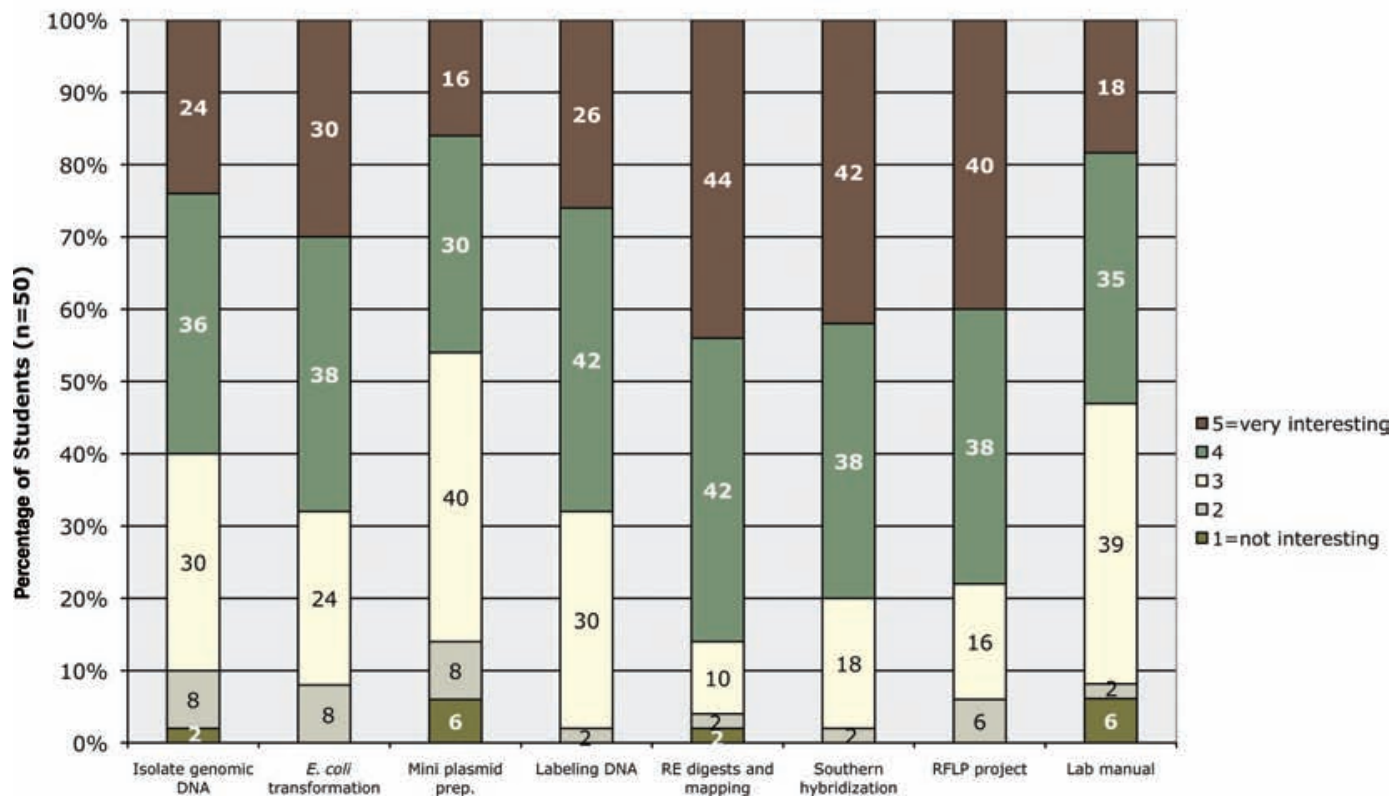

Figure 9. Responses to survey questions on the postquiz indicate that in general the laboratory project was not too difficult for the students, and it held their interest. Students ranked certain techniques and other aspects of the lab by order of difficulty, with selection of the number 1 being too difficult and number 5 very easy; students ranked interestingness with number 5 being very interesting and number 1 not interesting. The percentage of students $(n=50)$ answering in each category is shown. In most aspects, the majority of the students perceived difficulty to be on the easy side of neutral (between 2 and 3), and in most aspects the students thought the project interesting to very interesting (between 4 and 5).

(see below) suggest that the mapping of the wild-type and mutant genomes using the RFLP analysis was challenging. Yet at the same time, the RFLP project was thought to be interesting or very interesting by $78 \%$ of the students. The only lab to be considered more interesting, earning $4 \mathrm{~s}$ and $5 \mathrm{~s}$ by $86 \%$ of the students, was the one in which the students digested and mapped the plasmids they constructed. This lab was also considered to be the second to most challenging, with $45 \%$ of the students considering it to be difficult (or too difficult). That in these laboratory tasks the degree of perceived challenge is directly correlated with the degree of student interest is encouraging: Students are clearly not 
confusing interestingness with easiness; they appear to be appreciating what challenges them to think.

The postquiz also surveyed the students' opinions on safety by eliciting their ranking (strongly agree to strongly disagree) on the statement "My personal safety was never compromised-I had the needed protective equipment and clothing, and everyone in the lab was safety conscious." Out of 51 responses, $80 \%$ strongly agreed and 18\% agreed with the statement. Only one person ( $2 \%$ ) was neutral, and no one disagreed. Though the project as described here uses hazardous reagents (e.g., EtBr, phenol, and chloroform), much care was taken to reduce risks to the students and general public during their use and disposal. Instructors may want to investigate and use safer alternatives, such as GelRed (Biotium, Hayward, CA) for staining DNA and DNA purifying columns such as those sold by QIAGEN (Valencia, CA) to replace organic solvents. I continue to teach with $\mathrm{EtBr}$ and organic extractions because they are still widely used in research labs, and I would prefer that our budding scientists learn good habits of protecting themselves and their environment in a more supervised setting than when they move on to a more independent position.

In the postquiz, students were asked for their comments about the lab: what they found most interesting or least interesting and any other comments or suggestions for the future. A sampling of these are shown below:

What did you find was most interesting about the Molecular Biology Lab?

- I really liked that the entire lab was a project. It helped me understand what we were doing and why. (2008)

- What I found most interesting, but also the hardest in this lab was the RFLP project (and mapping). It was really neat to talk about mapping and steps towards the RFLP project in class; and I found it to be helpful (and interesting) that we did it in lab. (2008)

- I really enjoyed seeing everything come together over the course of the semester, I really felt like I learned more that way. Seeing the strands of DNA floating in the microfuge tube was one of the most memorable lab experiences I've ever had. I also really enjoyed doing restriction enzyme mapping, it's like a puzzle, which is fun. (2008)

- Using real experimental results to map a gene. (2008)

- Visualizing the Southern hybridization was very cool, because it was like the climax to weeks and weeks of work that we weren't even sure was successful until then. (2008)

- The use of consecutive labs working towards a specific project. It allows students to see how different techniques relate to one another and how they can be used in conjunction. (2007)

- The fact that we used the same techniques as real researchers made me feel like I WAS a real researcher. (2006)

- I liked that we completed a whole project. In labs I don't like doing something for no reason but in this lab everything we did brought us closer to our goal. (2006)

- We did everything on our own. We had to think about the lab before we started. It was not just put in front of us to do, volumes had to be measured, and the labs HAD to be read before class! I liked that the most about lab, it was challenging! (2005)
What did you find was the least interesting about the Molecular Biology Lab?

- The amount of work that had to be done at the end of the semester on the RFLP project was a little overwhelming. (2008)

- Running the gels, the down time, the feeling of "hurry up and wait." (2008)

- I'm biased because I found everything to be interesting, but the simpler labs such as performing RE digestions were a bit slow, although necessary. (2008)

- I know it is important for general lab knowledge, but the first lab, making solutions-ugh. (2007)

- Sitting around during long incubations, although that is life in the lab! (2006)

- The least interesting part of the lab was making the gel and phenol/chloroform extractions. (2005)

\section{Other comments or suggestions for the laboratory?}

- I would have liked to have done more restriction enzyme digests (for the RFLP project) of the mutant genome so that some ambiguities of the restriction enzyme sites could be resolved ... (2008)

- I felt like when we were working during the same lab on procedures of both sides of the flowchart that I sometimes confused myself on what belonged to what part of the experiment ... although I understand it teaches us to multitask in the lab. (2006)

- Allow students to do more of the "outside T[uesday] 1-4" lab work. Making gels (especially polyacrylamide) would have been good practice for us. (2006)

- Although I know not everything fits into the lab period, I would have liked to have the opportunity to do more of the protocol that [the instructor] had to do because of time issues. (2006)

- I sometimes felt rushed and would have liked to stick around longer to see results, so a 4-hour lab period would have been nice. (2005)

- Lab should be more than just one day a week. Although lab is long, there is always more to do! (2005)

These comments emphasize the students' desire to be challenged and to spend more time in the lab; some of them were disappointed that they did not do the tasks that I did outside of the regular lab period. I concur with the student opinions implying that a lab period of less than $3 \mathrm{~h} / \mathrm{wk}$ would not be satisfactory for this laboratory project. One can see from several positive comments, however, that many students appreciated the single long-term project approach as a way to learn applications of techniques and to analyze and interpret real data.

Some former students were compelled by their positive experiences in this laboratory to write me thank-you notes. R.S., who took the course in 2003, wrote, "I don't think I would be where I am today if it wasn't for the molecular and lab background you gave me." An earlier student (M.Z., 1999) had written, "I can say without a doubt that your class was by far the best bio class I've had ... The things we did in the lab are truly remarkable." Recent comments were solicited from both of these Millersville University alumni. R.S., who 
is now a biochemist at Merck and a master's student, wrote, "The molecular biology lab not only jump started my interest in molecular biology, but also gave me the fundamental background of molecular biology which helped me in future classes and continues to help me in my career ... the 12-week project pushed us to make sure we knew more than to just follow a protocol. We had to understand the purpose of each reagent and why we were performing each step." M.Z., who is now an assistant professor at Temple University, still remembers the course quite well. He had several positive comments, including, "Each lab not only introduced a new technique, but moved the semester project closer to its goal ... This left me not only with a familiarity with the execution of the techniques, but an intimate understanding of their purpose and utility in solving a specific scientific problem ... The integration of molecular biology into my own chemical interests has stemmed from this excellent course ... It is my opinion that your course could be used as a model, not only for other biology courses, but laboratory courses in other fields." After being hired as a technician at Cold Spring Harbor Laboratories, D.B. (2008) wrote, “... thank you for ... structur[ing] your classes the way you do. Several lab members have commented that I was very well prepared for the work ..." This lab has clearly influenced students in a positive manner, and that influence has the capacity to carry forward for years.

\section{CONCLUDING REMARKS}

One possible criticism of this laboratory project is that it yields data about a gene, dusky, that has already been determined. In fact, the labs are modeled after experiments actually done to clone the wild-type dusky gene (DiBartolomeis et al., 2002); hence, one might be concerned that students would be bored with the idea of repeating what has already been accomplished. Though it is true that if the goal of a particular course's lab is to perform original research, then this is not the lab to have one's students perform; if the objective is to teach students hands-on methodology and application of molecular techniques while giving them a flavor of real scientific research, then this lab project should be seriously considered. Students perform the exercises without knowing what the data will be, so it is in effect new to them. Indeed, student comments (above) indicate that the lab both was challenging and felt very realistic to them. That the instructor knows more than the students is beneficial because the consistency ensures that the students will be able to yield interpretable data, providing results that can be discussed in the format of a scientific paper.

Also adding to the students' excitement and involvement in the project is their knowledge that each person in the class depends on the results of every other person and that the final results are completely dependent on results of previous labs. So if a few students forget to add enzyme, DNA, or buffer to their digests, the mistake would not affect just them; it would also yield missing data that would affect everyone's analysis. This is also true of the solutions made in the first day of lab, since many, such as the $5 \mathrm{M} \mathrm{NaCl}$, were used as stocks for critical solutions such as hybridization, wash, and detection buffers. Though compensatory strategies such as duplicating digests and checking certain digests for completion were employed, this interdependency, albeit stressful, encouraged an attitude of teamwork and extra effort on the part of students and the instructor. For at least one student, "that the labs built on each other ... added a hint of 'danger' in the beginning if something wasn't done properly." This student seems to have taken a greater interest in his or her lab work because of the broader responsibility brought forth by such a long-term project. Moreover, this dependency on others' data and the checking of digests and other results in many cases reflects what occurs in real research laboratories as more and more projects are becoming interdisciplinary, and the average number of authors per publication increases. Still, it is important to realize that most likely the results will not be perfect, but they will be usable. If more time is available, or if part of a laboratory course includes an independent research project, there are many opportunities for repeating Southern hybridizations with different probes, genomic DNA digested with different enzymes, gels with higher or lower percentages of agarose, and so forth.

One intriguing aspect of this project is that it can be modified to make it more open ended and inquiry based. For example, in my course, I tell the students which restriction enzyme(s) to use to cut their genomic DNAs, based on which enzyme sites are already mapped in the $7.3-\mathrm{kb}$ region of wildtype DNA. If given the chance, however, students could probably come up with these enzymes themselves. Such decisions could be made individually, or students could be allowed to discuss the possibilities in groups and then defend their choices to the class. They can debate the worthiness of single digestions or double digestions as far as analyzing and interpreting the resulting RFLPs. In fact, if smaller wells are used on the gels, hence requiring less DNA and allowing for a greater number of wells, more digests than those described in this report could be performed. Also, any of a number of mini experiments can be performed within the main experiment. For example, the Fall 2008 class tested whether there was a difference in background on hybridizations performed with blots on uncharged nylon membrane or positively charged membrane. So half the blots were done using one type or the other (no obvious difference was noted). Another idea is to have students experiment with different methods of biotin detection (e.g., colorimetric vs. chemiluminescent). Of course, students can be encouraged to devise their own mini experiments, which they can design and carry out, presenting their results at the end of the semester.

A practical aspect of this project is that it does not require any specialized equipment or very expensive reagents. A molecular biology lab equipped with three microfuges, three vortex mixers, two hybridization (shaking) water baths, a table top centrifuge, four large submarine gel boxes, three minigel boxes, two midigel boxes, and the equivalent of two P2 Pipetman and six sets of Pipetman (P20, P100, P200, and P1000) is sufficient for six groups of four students each. With an initial investment of about $\$ 1200$ to purchase the nicktranslation kit, a roll of nylon membrane, DNA modifying enzymes, and other materials and reagents that last at least four to five semesters, the course costs about $\$ 800-\$ 1000$ per semester. Judging from the students' enthusiasm and interest as well as learning assessment results and its positive impact on career outcomes, this project is worth the efforts of the instructor and students and the monetary cost to the department. 


\section{ACCESSING MATERIALS}

The prequiz and postquiz used for the assessment are available online in the Supplemental Material. Instructors interested in using this laboratory project for their students are encouraged to contact me for any or all of the following: a CD-ROM of the lab manual (PDF/Word files) and a more detailed Materials and Methods, vials of Canton S and dusky ${ }^{73}$ flies, plasmid DNA and/or E. coli cells hosting the plasmid containing the 7.3-kb wild-type genomic region (or, if preferred, plasmid DNAs and/or E. coli cells hosting plasmids with the 2.6-kb genomic insert-both orientations), a complete restriction enzyme map of the 7.3-kb region (including the sites within the 2.6-kb fragment), and approximate maps of the Canton $S$ and $d y^{73}$ genomes in the dusky region (as derived from class results). No monetary compensation is required, and reagents may be shared with other educators; however, I request that the laboratory manual not be reproduced in full or in part in any manner for publication or sale. Requests may be sent to my email address: sdibarto@millersville.edu.

\section{ACKNOWLEDGMENTS}

I thank many companies that have donated reagents, instrumentation, or supplies or granted generous educational discounts, including Promega, GlaxoSmith Kline, Merck, Amersham/Pharmacia, and Owl Scientific. I am indebted to the students of Molecular Biology, Biology 462 (1991 to present day), for their patience and hard work in the lab and for their helpful suggestions and comments. This project was based on and uses reagents derived from my research in the laboratory of Dr. F. Rob Jackson, whom I thank for his valuable training and for granting me the opportunity to teach a molecular biology course while still a postdoctoral researcher. I also thank Dr. Jay Moné for his helpful comments about this manuscript. Some of the equipment used in this investigation was provided in part by funding from National Science Foundation Instrumentation and Laboratory Improvement grants.

\section{REFERENCES}

Allen D, Tanner K (2003). Approaches to cell biology teaching: learning content in context-problem-based learning. Cell Biol Educ 2, 73-81.

Ausubel FM, Brent R, Kingston RE, Moore DD, Seidman JG, Smith JA, Struhl K (2002). Current Protocols in Molecular Biology, New York: John Wiley \& Sons.

Bhattacharjee Y (2005). New curricula aim to make high school labs less boring. Science 310, 224-225.
DiBartolomeis SM, Akten B, Genova G, Roberts MA, Jackson FR (2002). Molecular analysis of the Drosophila miniature-dusky (m-dy) gene complex: $m$ - $d y$ mRNAs encode transmembrane proteins with similarity to C. elegans cuticulin. Mol Genet Genomics 267, 564-576.

DiBartolomeis SM, Moné JP (2003). Apoptosis: a four-week laboratory investigation for advanced molecular and cellular biology students. Cell Biol Educ 2, 275-295.

Dobzhansky T (1929). The influence of the quantity and quality of chromosomal material on the size of the cells in Drosophila melanogaster. Wilhelm Roux Arch Entwickl Mech Org 115, 363-379.

Dorn GL, Burdick AB (1962). On the recombinational structure and complementation relationships in the $m-d y$ complex of Drosophila melanogaster. Genetics 47, 503-518.

Green MM (1975). Genetic instability in Drosophila melanogaster: mutable miniature $\left(m^{\mu}\right)$. Mutat Res 29, 77-84.

Howard Hughes Medical Institute (1996). Beyond Bio 101: The Transformation of Undergraduate Biology Education, Chevy Chase, MD, www.hhmi.org/BeyondBio101 (accessed 26 July 2010).

Lefevre G (1981). The distribution of randomly recovered x-ray induced sex-linked genetic effects in Drosophila melanogaster. Genetics $99,461-480$.

Lindsley D, Zimm G (1992). The Genome of Drosophila melanogaster, San Diego, CA: Academic Press.

Maniatis T, Fritsch EF, Sambrook J (1982). Molecular Cloning: A Laboratory Manual, New York: Cold Spring Harbor Laboratory Press.

Mitchell BF, Graziano MR (2006). From organelle to protein gel: a 6-wk laboratory project on flagellar proteins. CBE Life Sci Educ 5, 239-246.

National Research Council (2003). Bio 2010, Transforming Undergraduate Education for Future Research Biologists, National Academies Press, Washington, DC. Www.nap.edu/catalog/ 10497.html (accessed 27 July 2010).

Newby L, White L, DiBartolomeis S, Walker B, Dowse H, Ringo J, Khuda N, Jackson F (1991). Mutational analysis of the Drosophila miniature-dusky $(m-d y)$ locus: effects on cell size and circadian rhythms. Genetics 128, 571-582.

Palombi PS, Jagger KS (2008). Learning about cells as dynamic entities: an inquiry-driven cell culture project. Bioscene 34(2), 27-33.

Sambrook J, Fritsch EF, Maniatis T (1989). Molecular Cloning: A Laboratory Manual, 2nd ed., New York: Cold Spring Harbor Laboratory Press.

Shane J (2009). Using NSTA's standards for science teacher preparation as a comprehensive framework for understanding and teaching science. J Penn Acad Sci 82, 102-106.

Sleister HM (2007). Isolation and characterization of Saccharomyces cerevisiae mutants defective in chromosome transmission in an undergraduate genetics research course. Genetics 177, 677-688. 